\title{
Ion beam induced modifications in electron beam evaporated aluminum oxide thin films
}

\author{
K.R. Nagabhushana ${ }^{a}$, B.N. Lakshminarasappa ${ }^{a, *}$, C. Pandurangappa ${ }^{a}$, Indra Sulania ${ }^{b}$, \\ P.K. Kulria ${ }^{\mathrm{b}}$, Fouran Singh ${ }^{\mathrm{b}}$ \\ a Department of Physics, Jnanabharathi Campus, Bangalore University, Bangalore 560 056, India \\ ${ }^{\mathrm{b}}$ Inter University Accelerator Centre, P.O. Box No. 10502, New Delhi 110 067, India
}

Received 23 September 2007; received in revised form 10 January 2008

Available online 29 January 2008

\begin{abstract}
$\mathrm{Al}_{2} \mathrm{O}_{3}$ thin films find wide applications in optoelectronics, sensors, tribology etc. In the present work, $\mathrm{Al}_{2} \mathrm{O}_{3}$ films prepared by electron beam evaporation technique are irradiated with $100 \mathrm{MeV}$ swift $\mathrm{Si}^{7+}$ ions for the fluence in the range $1 \times 10^{12}$ to $1 \times 10^{13}$ ions $\mathrm{cm}^{-2}$ and the structural properties are studied by glancing angle X-ray diffraction. It shows a single diffraction peak at $38.2^{\circ}$ which indicates the $\gamma$ phase of $\mathrm{Al}_{2} \mathrm{O}_{3}$. Further, it is observed that as the fluence increases up to $1 \times 10^{13}$ ions cm $\mathrm{cm}^{-2}$ the diffraction peak intensity decreases indicating amorphization. Surface morphology studies by atomic force microscopy show mean surface roughness of $34.73 \mathrm{~nm}$ and it decreases with increase in ion fluence. A strong photoluminescence (PL) emission with peak at $442 \mathrm{~nm}$ along with shoulder at $420 \mathrm{~nm}$ is observed when the samples are excited with $326 \mathrm{~nm}$ light. The PL emission is found to increase with increase in ion fluence and the results are discussed in detail.
\end{abstract}

(C) 2008 Elsevier B.V. All rights reserved.

PACS: 61.80.-Jh; 61.10.-Nz; 68.37.Ps; 78.66.-w

Keywords: $\mathrm{Al}_{2} \mathrm{O}_{3}$ thin films; Swift heavy ions; XRD; AFM; Photoluminescence

\section{Introduction}

Most solid state technologies are based on thin films. Thin films are usually prepared using vacuum techniques such as evaporation, sputtering or molecular beam epitaxy and is often combined to form complex multilayer structures for various applications. The most important microstructural properties of thin films are grain size, crystallographic texture and surface roughness [1]. $\mathrm{Al}_{2} \mathrm{O}_{3}$ is an important material used in planar wave guides because of its relatively high refractive index $(n=1.64)$ [2]. Further, $\mathrm{Al}_{2} \mathrm{O}_{3}$ films find wide applications - microelectronic devices, resistive coatings, catalysts, optoelectronics, sen-

\footnotetext{
* Corresponding author. Tel.: +91 94481 16281; fax: +91 8023219295

E-mail address: bnlnarasappa@gmail.com (B.N. Lakshminarasappa).
}

sors, tribology, corrosion protective coatings etc. $[3,4]$. Its wide usefulness is primarily due to its hardness, high melting point and low electrical conductivity at high temperature. Swift heavy ion irradiation is a unique post deposition treatment used to modify structural, optical and optoelectronic properties of thin film samples through the intense interaction of incident ions with the target atoms. There are several reports on structural and microstructural phase transformation due to irradiation using high energy heavy ions in thin films. Ratheesh Kumar et al. [5] have studied $100 \mathrm{MeV}$ Au ion irradiated $\operatorname{In}_{2} \mathrm{~S}_{3}$ thin films. They reported that on irradiation, crystallinity became poor and the sample became amorphous at $1 \times 10^{13}$ ions $\mathrm{cm}^{-2}$. Further, at $3 \times 10^{13}$ ions $\mathrm{cm}^{-2}$ the samples show recrystallization. Kumar et al. [6] reported swift heavy ion (SHI) induced optical modifications in LiF thin films. They studied $80 \mathrm{MeV}$ Ni ion induced color 
centers in LiF thin films using optical absorption and photoluminescence (PL) spectroscopy. Optical absorption studies show a broad band with peak at $445 \mathrm{~nm}$ corresponding to $\mathrm{F}_{2} / \mathrm{F}_{3}{ }^{+}$color centers. PL spectra show two broad bands of $\mathrm{F}_{2}$ and $\mathrm{F}_{3}{ }^{+}$color centers. The intensity of both the color centers increases up to $1 \times 10^{12}$ ions $\mathrm{cm}^{-2}$ followed by an exponential decrease.

Investigations of the radiation damage in $\mathrm{Al}_{2} \mathrm{O}_{3}$ under high energy heavy ion irradiation are currently a big problem [7]. Also, the study of radiation damage of $\mathrm{Al}_{2} \mathrm{O}_{3}$ has significance as this material is presently used in radiation dosimetry. In the present work, the effect of heavy ion irradiation on structural and optical properties of $\mathrm{Al}_{2} \mathrm{O}_{3}$ thin films has been studied and the results are reported.

\section{Experimental}

The $\mathrm{Al}_{2} \mathrm{O}_{3}$ films are deposited on Silicon $\langle 100\rangle$ substrate by an electron beam evaporation method under a vacuum of $10^{-6}$ Torr. Aluminum oxide samples (Sigma-Aldrich) are used as target. The substrates are kept at room temper- ature (RT). The thickness of the films of $100 \mathrm{~nm}$ is obtained by monitoring a quartz crystal oscillator during deposition. After deposition, the films are annealed at $500{ }^{\circ} \mathrm{C}$ for three hours in oxygen atmosphere in a tubular furnace. One of these films is kept as pristine and the other films are irradiated with $100 \mathrm{MeV}$ swift $\mathrm{Si}^{7+}$ ions for the fluence in the range $1 \times 10^{12}$ to $1 \times 10^{13}$ ions $\mathrm{cm}^{-2}$ using the 15 UD Pelletron at Inter University Accelerator Centre, New Delhi. The glancing angle $\left(1^{\circ}\right) \mathrm{X}$-ray diffraction (GAXRD) studies are carried out for structural characterization using Brucker AXS X-ray diffractrometer. Surface morphology is studied using Digital Instruments, Nanoscope IIIa, atomic force microscope (AFM) in the Tapping mode. PL studies are performed using excitation by $326 \mathrm{~nm}$ from $\mathrm{He}-\mathrm{Cd}$ laser (KIMMON) and Mechelle900 spectrograph in 200$1100 \mathrm{~nm}$ wavelength region. The PL setup has a cooled CCD array-based detection system. The laser light is incident on the sample at $45^{\circ}$ and the luminescence light is collected using a collector assembly and transmitted to the spectrograph through optical fiber for detection and analysis.

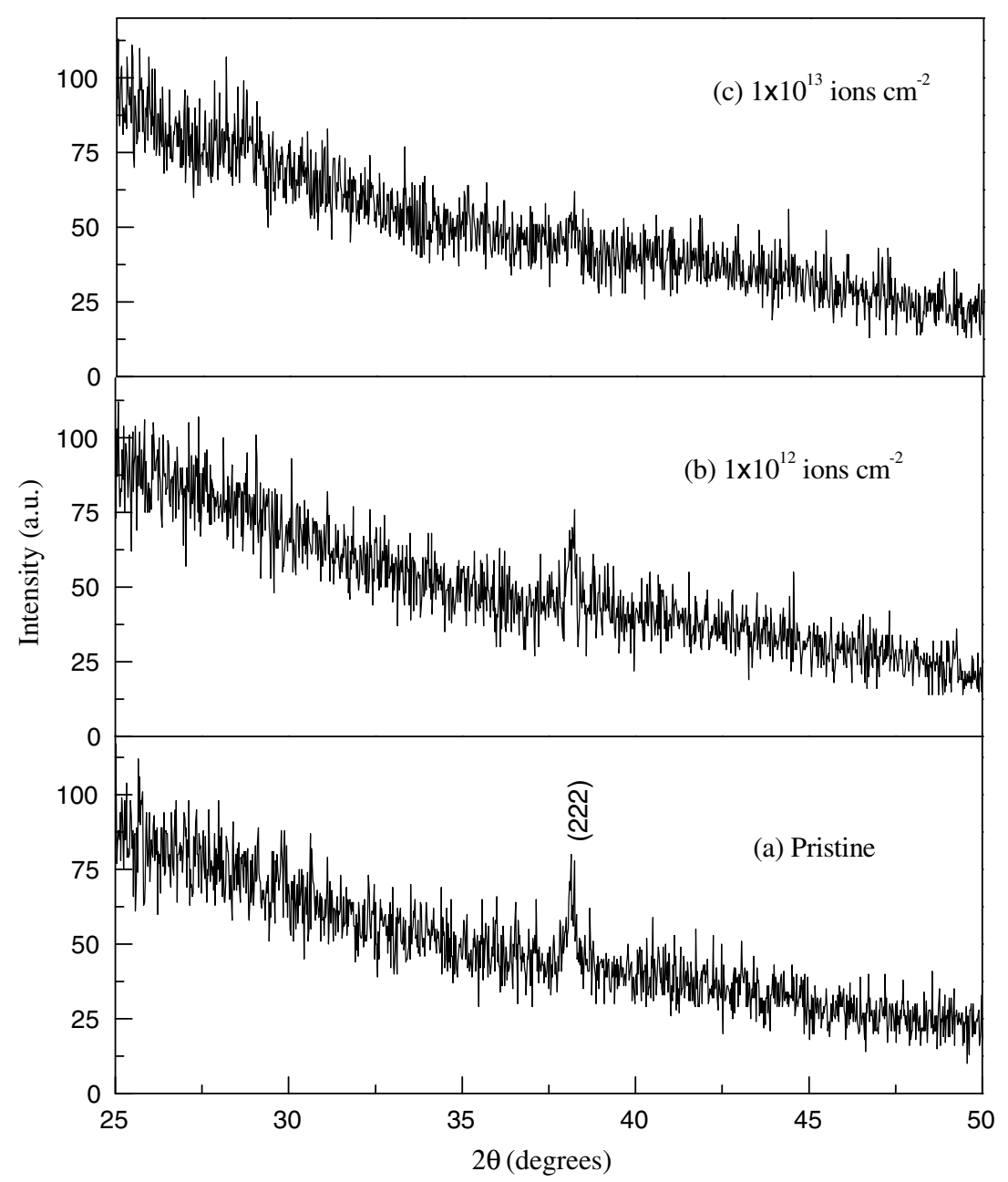

Fig. 1. Glancing angle $\left(1^{\circ}\right) \mathrm{X}$-ray diffraction patterns of electron beam evaporated $\mathrm{Al}_{2} \mathrm{O}_{3}$ thin films annealed at $500{ }^{\circ} \mathrm{C}$ (a) pristine and (b) and (c) $100 \mathrm{MeV}$ $\mathrm{Si}^{7+}$ ion irradiated films. 


\section{Results and discussions}

\subsection{Glancing angle X-ray diffraction}

When an energetic ion passes through a matter, it loses energy by elastic scattering (nuclear energy loss) and inelastic scattering (electronic energy loss). The electron energy loss $\left(S_{\mathrm{e}}\right)$ and nuclear energy loss $\left(S_{\mathrm{n}}\right)$ of $100 \mathrm{MeV} \mathrm{Si}^{7+}$ ions in $\mathrm{Al}_{2} \mathrm{O}_{3}$ matrix is calculated using SRIM 2003 program and the values are estimated to be $4.412 \mathrm{keV} \mathrm{nm}^{-1}$ and $0.003 \mathrm{keV} \mathrm{nm}^{-1}$ respectively and the range for $\mathrm{Si}^{7+}$ ions is calculated to be $19.6 \mu \mathrm{m}$. The GAXRD patterns of electron beam evaporated, $500{ }^{\circ} \mathrm{C}$ annealed (a) pristine and (b and c) $100 \mathrm{MeV} \mathrm{Si}^{7+}$ ion irradiated aluminum oxide films are shown in Fig. 1. In the pristine film a diffraction peak at $38.2^{\circ}$ due to $(222)$ reflection is observed. As we know the $\mathrm{Al}_{2} \mathrm{O}_{3}$ exists in several distinct crystallographic phases such as $\gamma, \delta, \theta$ and $\alpha-\mathrm{Al}_{2} \mathrm{O}_{3}$. The observed diffraction peak is attributed to $\gamma$ phase of aluminum oxide [8]. It is observed that the diffraction peak intensity decreases for the films irradiated with fluence $1 \times 10^{12}$ ions $\mathrm{cm}^{-2}$. Further, with increase in ion fluence the diffraction peak completely disappears at $1 \times 10^{13}$ ions $\mathrm{cm}^{-2}$. The sample in this case is amorphized as a result of cascade quenching with swift heavy ion irradiation [9]. The possible explanation for this kind of structural modification induced by SHI irradiation can be explained by total energy deposited in electronic excitations or ionizations in the films by energetic ions. The imparted energy of the incoming ions in our films at higher fluence may lead to overlapping of tracks to promote lattice disordering inside large grains [10].
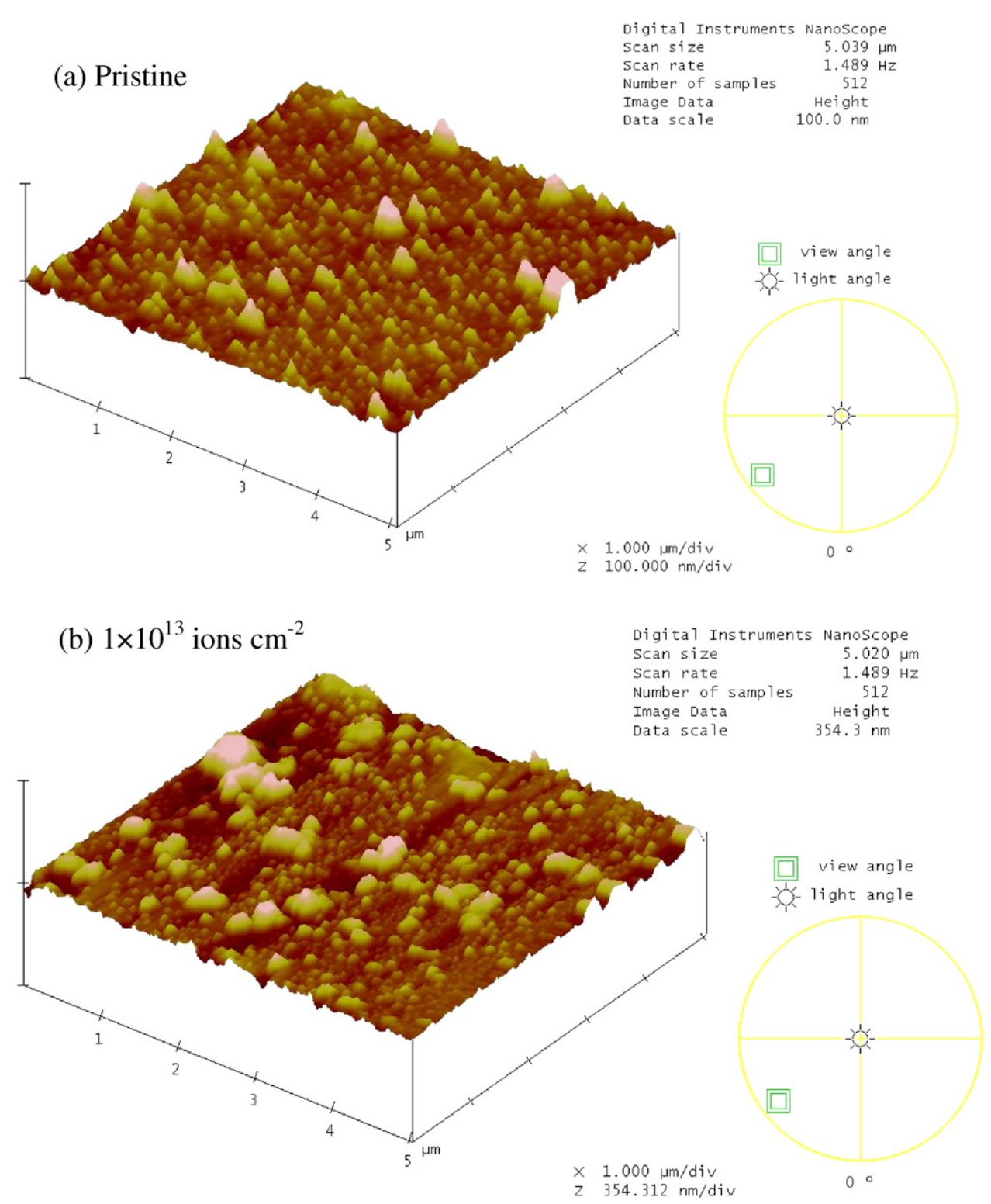

Fig. 2. AFM images of (a) pristine and (b) $1 \times 10^{13}$ ions $\mathrm{cm}^{-2}$ irradiated $\mathrm{Al}_{2} \mathrm{O}_{3}$ thin films. 


\subsection{Atomic force microscopy}

AFM is a very effective tool for examining surface modifications and surface structures and can be applied to understand the modification in the roughness and morphology of films upon SHI irradiation. Fig. 2 shows $5 \times 5 \mu \mathrm{m}^{2}$ 3 D-images of (a) pristine and (b) $1 \times 10^{13} \mathrm{Si}^{7+}$ ions $\mathrm{cm}^{-2}$ irradiated aluminum oxide films. It is observed that conical shaped hillocks are uniformly distributed in pristine sample. In samples irradiated with $1 \times 10^{13}$ ions $\mathrm{cm}^{-2}$, the conical shaped hillocks disappear and randomly distributed granular shaped hillocks have been observed as can be seen from Fig. 2(b). Also, the surface is smoother in irradiated sample than the pristine one. The roughness of the films was estimated by the software attached with Nanoscope IIIa. The $5 \times 5 \mu \mathrm{m}^{2}$ images are utilized for measuring the surface roughness of the films. The roughness of pristine film is measured to be $34.73 \mathrm{~nm}$. Further, the roughness of the samples decreases with increase in ion fluence. The roughness of $1 \times 10^{12}, 5 \times 10^{12}$ and $1 \times 10^{13}$ ions $\mathrm{cm}^{-2}$ is found to be $29.49,17.85$ and $9.28 \mathrm{~nm}$, respectively. The decrease in surface roughness value might be due to discontinuous tracks that may lead to amorphization as well as simple defects such as color centers. The XRD results revealed the amorphization of films as discussed in Section 3.1

\subsection{Photoluminescence}

The defects production mechanism may be understood by PL technique. PL is a very sensitive tool as compared to the optical absorption for the lower concentration of defects. Further, from PL studies one can identify the presence of defects whose optical absorption bands overlap. Fig. 3 shows the photoluminescence spectra of electron beam evaporated $\mathrm{Al}_{2} \mathrm{O}_{3}$ thin films irradiated with $100 \mathrm{MeV} \mathrm{Si}{ }^{7+}$ ions. When these samples are excited at $326 \mathrm{~nm}$ light the pristine films show very weak luminescence response while

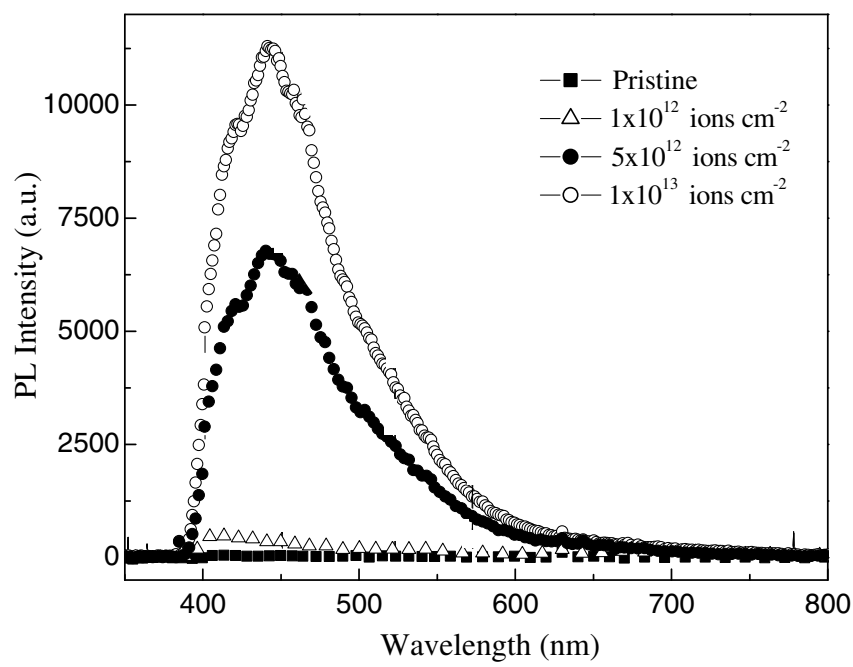

Fig. 3. Photoluminescence $\left(\lambda_{\mathrm{ex}}=326 \mathrm{~nm}\right)$ spectra of pristine and $100 \mathrm{MeV} \mathrm{Si}^{7+}$ ion irradiated $\mathrm{Al}_{2} \mathrm{O}_{3}$ thin films.

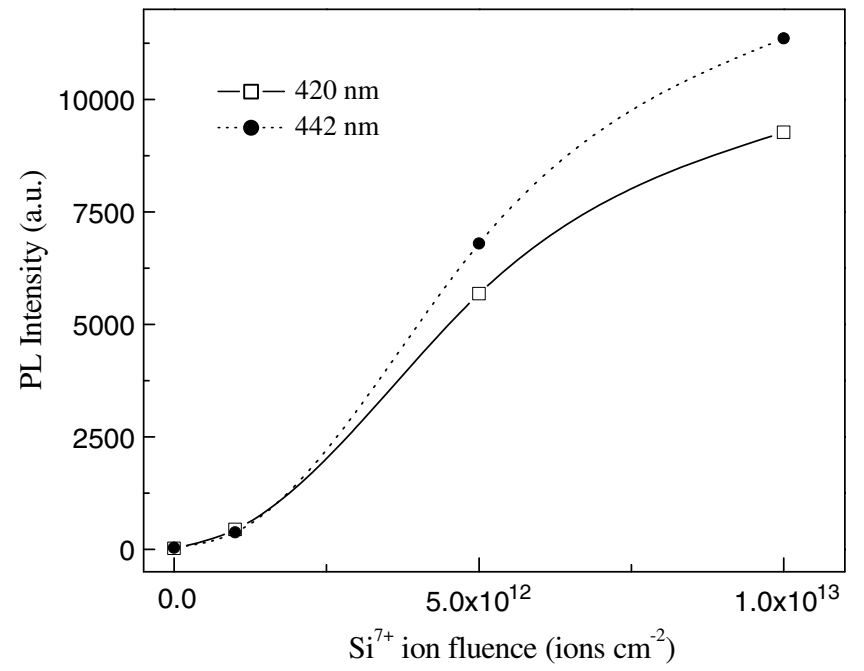

Fig. 4. Variation of $\mathrm{PL}$ intensity with ion fluence in $100 \mathrm{MeV} \mathrm{Si}^{7+}$ ion irradiated $\mathrm{Al}_{2} \mathrm{O}_{3}$ thin films.

SHI irradiated films shows a prominent and strong PL emission with peak at $442 \mathrm{~nm}$ along with shoulder at $420 \mathrm{~nm}$. These emission bands arise from SHI induced color centers such as $\mathrm{F}$ and $\mathrm{F}_{2}{ }^{2+}$-centers, respectively. Skuratov and coworkers [11] studied the radiation damage under $245 \mathrm{MeV}$ swift $\mathrm{Kr}$ ion irradiation in aluminum oxide. They reported three PL emissions with peaks at 330, 420 and $510 \mathrm{~nm}$ and ascribed to $\mathrm{F}^{+}, \mathrm{F}$ and $\mathrm{F}_{2}$-centers, respectively. Therefore, it is believed that $420 \mathrm{~nm}$ PL emission in the present studies may be attributed to F-centers. Further, the prominent PL emission at $442 \mathrm{~nm}$ might be due to $\mathrm{F}_{2}{ }^{2+}$-centers. Song et al. [12] have studied the photoluminescence using $350 \mathrm{~nm}$ light as excitation source in $230 \mathrm{MeV} \mathrm{Pb}$ ion irradiated aluminum oxide. They reported PL emission with peak at 380, 413, 450 and $516 \mathrm{~nm}$ in irradiated samples. They attributed the $450 \mathrm{~nm}$ emission to latent excitation luminescence of $\mathrm{F}_{2}{ }^{2+}$-centers whereas PL emission at 380 , 413 and $516 \mathrm{~nm}$ were attributed to $\mathrm{F}_{2}{ }^{+}, \mathrm{F}$ and $\mathrm{F}_{2}$-centers respectively. Hence, $442 \mathrm{~nm}$ emission in the present work may be attributed to latent excitation luminescence of $\mathrm{F}_{2}{ }^{2+}$-centers. However, electron spin resonance (ESR), Raman spectroscopy etc., studies may throw some light on better understanding of the defects responsible for luminescence. Fig. 4 shows the variation of PL intensity at 420 and $442 \mathrm{~nm}$ with ion fluence. The data point at zero fluence represents the PL intensity of unirradiated films. It is observed that PL intensity is low at $1 \times 10^{12}$ ions $\mathrm{cm}^{-2}$ and it increases after $5 \times 10^{12}$ ions $\mathrm{cm}^{-2}$. This can be attributed to increase in concentration of color centers responsible for luminescence through radiative recombination [13].

\section{Conclusions}

Electron beam evaporated $\mathrm{Al}_{2} \mathrm{O}_{3}$ thin films annealed at $500{ }^{\circ} \mathrm{C}$ show a single XRD peak at $38.2^{\circ}$ which indicate $\gamma$ phase of $\mathrm{Al}_{2} \mathrm{O}_{3}$. The films are amorphized when irradiated with $100 \mathrm{MeV} \mathrm{Si}^{7+}$ ions for the fluence $1 \times 10^{13}$ ions $\mathrm{cm}^{-2}$. 
The pristine film shows roughness of $34.73 \mathrm{~nm}$. The roughness of the irradiated films decreases with increase in ion fluence and is found to be $9.28 \mathrm{~nm}$ at $1 \times 10^{13}$ ions $\mathrm{cm}^{-2}$. The decrease in surface roughness is attributed to discontinuous tracks that may lead to amorphization. Further, the irradiated films show a prominent and strong PL emission with peak at $442 \mathrm{~nm}$ along with shoulder at $420 \mathrm{~nm}$. In pristine and samples irradiated at lower fluence, the PL emission is very weak and PL intensity shoots up at and above $1 \times 10^{12}$ ions $\mathrm{cm}^{-2}$. This is due to increase in concentrations of color centers. The $442 \mathrm{~nm}$ emission is attributed to latent excitation luminescence of $\mathrm{F}_{2}^{2+}$-center and $420 \mathrm{~nm}$ emission is attributed to F-centers.

\section{Acknowledgements}

The authors express their sincere thanks to Dr. Kabiraj and Sri. S.R. Abhilash, Target Laboratory, Inter University Accelerator Centre, New Delhi for their help in preparation of films. One of the authors (KRN) is grateful to IUAC for providing fellowship.

\section{References}

[1] M. Vopsaroiu, G. Vallejo Fernandez, M.J. Thwaites, J. Anguita, P.J. Grundy, K.O. Grady, J. Phys. D: Appl. Phys. 38 (2005) 490.

[2] X.J. Wang, M.K. Lei, Thin Solid Films 476 (2005) 41.

[3] I.Y. Konyashin, Surf. Coat. Technol. 85 (1996) 131.

[4] T. Mimani, Resonance 5 (2000) 50.

[5] P.M. Ratheesh Kumar, Teny Theresa John, C. Sudha Kartha, K.P. Vijayakumar, Nucl. Instr. and Meth. B 244 (2006) 171.

[6] M. Kumar, F. Singh, S.A. Khan, A. Tripathi, D.K. Avasthi, A.C. Pandey, Nucl. Instr. and Meth. B 244 (2006) 183.

[7] V.A. Skuratov, V.A. Altynov, S.M. Abu AlAzm, Nucl. Instr. and Meth. B 107 (1996) 263.

[8] T. Peng, X. Liu, Ke Dai, et al., Mater. Res. Bull. 41 (2006) 1638.

[9] T. Diaz de la Rubia, G.H. Gilmer, Phys. Rev. Lett. 74 (1995) 2507.

[10] R. Kumar, R.J. Choudhary, S.I. Patil, S. Hussain, J.P. Srivastava, P. Sanyal, S.E. Lofland, Appl. Phys. 96 (2004) 7383.

[11] V.A. Skuratov, Kim Jong Gun, J. Stano, D.L. Zagorski, Nucl. Instr. and Meth. B 245 (2006) 194.

[12] Y. Song, C.H. Zhang, Z.G. Wang, Y.M. Sun, J.L. Daun, Z.M. Zhao, Nucl. Instr. and Meth. B 245 (2006) 120.

[13] K.R. Nagabhushana, B.N. Lakshminarasappa, G.T. Chandrappa, D. Haranath, Fouran Singh, Radiat. Eff. Defect. Solids 162 (2007) 325. 